\title{
Citrobacter freundii and Acinetobacter baumanii infection in a patient with neoplastic lung disease - Case report
}

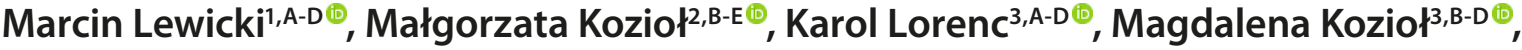 \\ Mateusz Pawlicki ${ }^{3, \mathrm{~B}-\mathrm{D} \oplus}$, Agata Smoleń ${ }^{1, \mathrm{~A}, \mathrm{D}-\mathrm{F} \oplus}$ \\ 1 Department of Epidemiology and Clinical Research Methodology, Medical University, Lublin, Poland \\ ${ }^{2}$ Chair and Department of Medical Microbiology, Medical University, Lublin, Poland \\ ${ }^{3}$ Student Scientific Association at Department of Epidemiology and Clinical Research Methodology, Medical University, \\ Lublin, Poland \\ A - Research concept and design, B - Collection and/or assembly of data, C - Data analysis and interpretation, \\ $D$ - Writing the article, $E$ - Critical revision of the article, $F$ - Final approval of the article
}

\begin{abstract}
Lewicki M, Kozioł M, Lorenc K, Kozioł M, Pawlicki M, Smoleń A. Citrobacter freundii and Acinetobacter baumanii infection in patient with
\end{abstract} neoplastic lung disease. Case report. Ann Agric Environ Med. 2021; 28(4): 724-728. doi: 10.26444/aaem/140111

\begin{abstract}
An 85-year-old male with a tumour in his right lung was admitted to Internal Diseases Ward to continue treatment after suffering a sudden cardiac arrest. An empiric antibiotic therapy with amoxycillin was introduced due to increased inflammation markers. Blood and sputum were collected. An abundant growth of AmpC $\beta$-lactamase-producing Citrobacter freundii was observed in culture grown from the sputum. The antibiogram showed retained sensitivity to fluoroquinolones. The therapy was modified by replacing $\beta$-lactam with ciprofloxacin. Neither clinical nor laboratory improvement were observed. Blood culture indicated sepsis of Acinetobacter baumannii etiology. The strain was suspected of producing OXA carbapenemase (CARBA test positive), KPC (-), MBL (-). Antibiogram illustrated retained sensitivity to gentamicin and colistin with complete resistance to ciprofloxacin. Another modification in treatment was implemented and ciprofloxacin was replaced with colistin.
\end{abstract}

- Key words

antibiotic resistance, antibiotic therapy, alert pathogen

\section{INTRODUCTION}

Lung cancer is the most frequent type of malignant neoplasm among the Polish population. It is characterized by unfavourable prognosis with one of the lowest five-year survival estimates. In 2017, in Poland alone it was diagnosed in 13,798 men and 7,747 women. At the same time, 15,499 men and 7,825 women died due to this form of malignancy [1]. It is the first cancer-related cause of death among both men and women [2]. The course of the disease may be complicated by various accompanying conditions: from pulmonary fibrosis to infections due to impaired immunity. One of the most commonly occurring complications of lung cancer is pulmonary infection (50-70\% of cases) [3]. The prognosis is influenced not only by the patient's condition, but also risk factors dependent on the environment and virulence of the pathogens. As a result of recurrent infections and broad-spectrum antibiotic therapy, pathogens able to develop defense mechanisms against different groups of antibiotics are often isolated. Those pathogens isolated from infections are more often non-susceptible to most available drugs by producing resistance mechanisms. They have been classified as so called 'alert pathogens'.

Microbial resistance to drugs is currently one of the major problems in antibiotic therapy, particularly in hospital-

Address for correspondence: Karol Lorenc, Student Scientific Association at Department of Epidemiology and Clinical Research Methodology, Medical University, Radziwiłłowska 11, 20-080 Lublin, Poland

E-mail: lorenckarol2@gmail.com

Received: 18.12.2020; accepted: 08.07.2021; first published: 20.07.2021 acquired infections where several pathogens can persist in the environment for extended periods of time,the and serve as vehicles of transmission and dissemination in the hospital setting. Cross-transmission of these pathogens can occur via the hands of healthcare workers who become contaminated directly from patient contact, or indirectly by touching contaminated environmental surfaces. Alert pathogens can cause severe, difficult to manage infections, which significantly increases morbidity and mortality rates, especially among elderly oncological patients with additional risk factors, e.g. concomitant cardio-vascular disease.

Pneumonia or sepsis, as a complication in patients with lung cancer, has mainly a gram-negative etiology. Most infections are caused by bacilli from the Enterobacteriaceae family, such as Citrobacter spp. or Acinetobacter spp., which tend to be a recurrent problem, including healthcareassociated infections, mostly in intensive care units, less often in general and vascular surgery wards where numerous invasive procedures are performed. The biggest challenge is to make a proper therapeutical decision considering the growing drug resistance of the bacteria [4].

\section{OBJECTIVE}

The aim of this study is to present the case report of a patient with a history of small-cell lung cancer who developed infectious complications. The bacterial strains responsible for the infection are discussed, with special consideration of the implemented antibiotic therapy available at the time. 
This case seems to be important not only for medical, but also economic reasons as the costs of both diagnostics and treatment in alert pathogen-related lung infection require considerable financial resources

\section{CASE REPORT}

The patient was an 85-year-old man who after sudden cardiac arrest in a Primary Care Physician Clinic was successfully reanimated and after emergency intubation was admitted to the District Department of Internal Diseases with Cardiological Sub-unit. He had previously been hospitalized in a Tuberculosis and Pulmonary Diseases Sanatorium. In his disease history, the patient had heart ischemic disease, chronic mixed bronchitis, generalized atherosclerosis, and right lung tumour with malignant characteristics. He was extubated on the ward and continued breathing on his own. Chest X-ray showed a known $4 \times 4 \mathrm{~cm}$ tumour in the right lung, with additional parenchymal and inflammatory consolidations. Material was taken for basic laboratory tests. Increased inflammatory markers were observed in blood: WB $13.6 \times 10^{3} / \mathrm{mm}^{3}$ - leukocytosis, CRP: $38.80 \mathrm{mg} / \mathrm{dl}$ [norm $<5 \mathrm{mg} / \mathrm{dl}$ ]. Urinalysis was performed during the second day of hospitalization and numerous bacteria were observed in the field of view. Because of the patient's medical condition: fever, persistent cough and increased inflammatory markers, microbiological examination was ordered. Samples of blood and sputum culture were collected, and empiric antibiotic therapy with amoxicillin and clavulanic acid introduced. A blood culture test showed no sign of a blood infection. Material from the lower respiratory tract showed an abundant growth of gram-negative Citrobacter freundii bacilii, the strain that produced type AmpC $\beta$-lactamase (alert pathogen). Additionally, mycological cultures revealed a quite significant growth of yeasts from the Candida genus (Candida albicans). The bacterial strain showed in vitro sensitivity to aminoglycosides, trimethoprim/sulfamethoxazole and fluoroquinolones, along with resistance to amoxicillin with clavulanic acid which were used at this time. A detailed antibiogram of the C. freundii strain is showed in Table 1.

Table 1. Drug sensitivity of Citrobacter freundii isolated from patient's lower airways, along with minimal inhibitory concentration values (MIC) [interpretation according to EUCAST recommendations]

\begin{tabular}{lcc}
\hline Antibiotic & S- sensitive; R- resistant & $\mathrm{MIC}[\mu \mathrm{g} / \mathrm{ml}]$ \\
\hline Amoxicillin/Clavulanic $a$. & $\mathrm{R}$ & 16 \\
\hline Piperacillin/Tazobactam & $\mathrm{S}$ & $\leq 4$ \\
\hline Ceftazidime & $\mathrm{S}$ & 0.25 \\
\hline Gentamicin & $\mathrm{S}$ & $\leq 1$ \\
\hline Amikacin & $\mathrm{S}$ & $\leq 2$ \\
\hline Tobramycin & $\mathrm{S}$ & $\leq 1$ \\
\hline Cefotaxime & $\mathrm{S}$ & $\leq 0.25$ \\
\hline Ciprofloxacin & $\mathrm{S}$ & $\leq 0.25$ \\
\hline Sulfamethoxazole/Trimethoprim & $\mathrm{S}$ & $\leq 20$
\end{tabular}

The treatment was modified according to the obtained antibiogram, and antibiotic de-escalating therapy was introduced. Ciprofloxacin in intravenous administration $2 \times$ $400 \mathrm{mg} /$ day was implemented. Despite these modifications, the clinical condition of the patient did not improve.
Inflammatory markers during day 18 of hospitalization: WBC: $11.6 \times 10^{3} / \mathrm{mm}^{3}$; CRP: $203.21 \mathrm{mg} / \mathrm{dl}$. Due to persisting high levels of inflammatory markers, pneumonia, continuous subfebrile state and impaired consciousness, a blood culture test was performed again on the day 21 of hospitalization.

Growth of another gram-negative bacillus, Acinetobacter baumannii, was obtained. Gathered data, in correlation with the patient's clinical condition, indicated the development of severe sepsis. According to the Carba NP test, the isolated strain was suspected of producing class D metallo- $\beta$ lactamases - OXA. An infection with another alert pathogen was diagnosed. An antibiogram was made; results are presented in Table 2 .

Table 2. Drug sensitivity of Acinetobacter baumannii isolated from patient's blood, along with MIC values [interpretation according to EUCAST recommendations]

\begin{tabular}{lcc}
\hline Antibiotic & $\begin{array}{c}\text { S- sensitive; R- resistant; I- } \\
\text { Intermediate }\end{array}$ & MIC [ $\mathrm{gg} / \mathrm{ml}]$ \\
\hline Piperacillin & $\mathrm{R}$ & $>64$ \\
\hline Tikarcillin/Clavulanic $a$. & $\mathrm{R}$ & $>64$ \\
\hline Piperacillin/Tazobactam & $\mathrm{R}$ & $>64$ \\
\hline Ceftazidime & $\mathrm{R}$ & $>32$ \\
\hline Imipenem & $\mathrm{R}$ & $>8$ \\
\hline Meropenem & $\mathrm{R}$ & $>8$ \\
\hline Gentamicin & $\mathrm{S}$ & 4 \\
\hline Tobramycin & $\mathrm{R}$ & 8 \\
\hline Ciprofloxacin & $\mathrm{R}$ & $<2$ \\
\hline Cefepime & $\mathrm{I}$ & 8 \\
\hline Levofloxacin & $\mathrm{R}$ & $>4$ \\
\hline Colistin & $\mathrm{S}$ & $>160$ \\
\hline Sulfamethoxazole/Trimethoprim & $\mathrm{R}$ & 1 \\
\hline
\end{tabular}

An interesting finding in the A. baumannii antibiogram was the preserved gentamicin and colistin sensitivity with complete resistance to ciprofloxacin which had been used previously. The treatment was adjusted by replacing it with colistin. A rapid improvement in the clinical condition with a simultaneous reduction of inflammatory markers was obtained after intravenous dosage of $3 \times 2$ million units/day.

On the day of the patient's discharge, the parameters were as follows: WBC $\left(7.2 \times 10^{3} / \mathrm{mm}^{3}\right)$, CRP $(4.41 \mathrm{mg} / \mathrm{dl})$ and were within the reference range. The patient was discharged in good general condition on day 31 of hospitalization. Originally admitted to the ward for the treatment of infection, lung cancer was subsequently diagnosed and treated by oncologists. The further fate of the patient is unknown.

Table 3. Changes in CRP and WBC during hospitalization

\begin{tabular}{lccccc}
\hline Day & 1 & 12 & 18 & 27 & 31 \\
\hline CRP- quantitative $[\mathrm{mg} / \mathrm{dl}]$ & 38.80 & 232.95 & 203.21 & 6.61 & 4.41 \\
\hline WBC $\left[\times 10^{3} / \mathrm{mm}^{3}\right]$ & 13.6 & 20.0 & 11.6 & 8.4 & 7.2 \\
\hline
\end{tabular}

\section{DISCUSSION}

Lung cancer is the one of the most frequent types of malignancy in men, estimated to be responsible for $1 / 3$ of 
cases and $1 / 5$ of deaths [1]. As indicated by the National Cancer Register (Krajowy Rejestr Nowotworów), in 2014, it was the most frequently noted cancer (18.5\%). Lung cancer, due to its localization and bad prognosis, contributes to many complications. According to data based on 100 autopsies, the most common fatal complications are: emphysema (30\%), infections (24\%), organ failure (23\%), pulmonary oedema (15\%), pulmonary embolism (12\%), pulmonary fibrosis (10\%), chronic obstructive pulmonary disease $(8 \%)$, and complications after radio- (9\%) and chemotherapy (7\%) [5]. Elderly people are particularly at risk. About $69 \%$ of new diagnoses are patients above the age of 65 [6], although active smoking still remains the leading cause of the disease, along with asbestos, nickel, chromium, arsenic, radiation, radon gas at houses and air pollution [7]. A typical cause of dangerous lethal complications are infections, especially with so-called alert pathogens which must be reported and registered to local sanitary-epidemiological stations. The list consists of multi-drug resistant pathogens, such as Staphylococcus aureus - MRSA (methicillin-resistant S. aureus), VISA (vancomycinintermediate) or VRSA (vancomycin-resistant); enterococci strains resistant to vancomycin - VRE (vancomycinresistant) or oxazolidinones; Streptococcus pneumoniae - resistant to third generation cephalosporins, penicillin PRSP (penicillin-resistant). Moreover, microorganisms from Enterobacteriaceae family with different mechanisms of resistance, such as extended spectrum beta-lactamases (ESBL) producing $\beta$-lactamases able to perform hydrolysis of penicillins, cephalosporins and aztreonam; strains producing AmpC cephalosporinases conditioning resistance to $\beta$-lactamase antibiotics (which hydrolyze penicillins, part of cephalosporins and aztreonam); strains producing class A carbapenemases- KPC (Klebsiella pneumoniae carbapenemase) hydrolyzing all essential $\beta$-lactamases; strains producing the most specialized carbapenemases of class B and type MBL (metallo- $\beta$-lactamases); NDM-1 strains (New Delhi metallo- $\beta$-lactamase); strains producing class D carbapenemases from the CHDL group (OXA type)carbapenem-hydrolyzing class D $\beta$-lactamases) $[8,9,10]$.

Both cancer and its treatment cause disturbances of innate and adaptive response to bacteria in the lungs. Lack of leukocytes or interruptions of their sequestration, dysregulated inflammation, mucosal disruptions, problems with recognizing pathogens, anatomical anomalies bounded with cancer and 'graft versus host' type of responses - all of which contribute to the great susceptibility of cancer patients to lower respiratory tract infections. Additionally, persistent contact with healthcare facilities increases exposition to multi-drug resistant pathogens [11].

Citrobacter spp. is a gram-negative bacillus from the Enterobacteriaceae family and can be isolated from various clinical samples: sputum, tracheal aspirate, blood, pus, urine and surface of catheters. Thus, it can be the cause of various types of infections of the urinary tract, respiratory system or the blood [12]. So far, Citrobacter spp. infections have been relatively rare, encountered mainly at Intensive Care Units. Unfortunately, in the last few years, an upward trend has been seen in Citrobacter freundii isolates among hospital infections [13]. The percentage of lethal cases among those infected in hospitals is approximately $6.8 \%$, but this may significantly increase to $17.8-56 \%$ if the patient develops bacteriaemia [12]. Today, Citrobacter spp. infections require longer hospitalization with higher hospitalization charges due to bacterial drug-resistance $[14,15]$. AmpC expression and selection of ESBL strains may be induced by prior antibiotic usage [16]. These strains are often responsible for the failure of standard antibiotic therapy, and significantly influence mortality rates.

Many negative prognostic factors during Citrobacter freundii blood infections have been noted. Some of them are hypothermia, oliguria, hyperbilirubinemia, azotemia and thrombocytopenia. Blood infections are mainly secondary, and therefore the source of pathogens can be found in the urinary tract, abdomen, contaminated vascular catheters and lower respiratory tract (pneumonia) [17].

C. freundii infection described in the presented case report concerned the lower respiratory tract, the source of the sputum used for diagnostics. Although the pathogen growth was abundant, further blood infection did not develop, even though the bacterium was qualified as capable of producing AmpC $\beta$-lactamase. The level of strain resistance depends on the level of enzyme expression [8]. AmpC cephalosporinases which hydrolyze penicillins are typically not vulnerable to classical $\beta$-lactamase inhibitors, and are resistant to some or all cephalosporins $[9,18]$. However, sensitivity of the strain to piperacillin/tazobactam or some cephalosporins has been noted, which could be because the in vitro conditions may result from lowered sensitivity to these drugs. A similar situation has been observed by Razeai et al. in their research on most hospital C. freundii isolates [13]. On the other hand, Indian research showed that even if there was a higher percent of strains sensitive to piperacillin with inhibitor, it was often related to very high resistance to cephalosporins, aminoglycosides or fluoroquinolones. What is more $54 \%$ of these strains were ESBL [19]. Considering the clinical aspect both ESBL+ pathogens, and those with acquired AmpC, they pose a similar level of threat. Nonetheless, from the epidemiological point of view, ESBL are more common and present a higher risk of infection [8].

Acinetobacter baumannii is another important gramnegative bacillus which in the past was thought to be low category pathogen, but nowadays it turns out to be one of the dominant etiological factors of hospital-acquired infections. It often attacks the lower airway, patients with impaired immunity and mechanically ventilated patients, leading to Ventilator Associated Pneumonia or bacteriemia. Therefore, it appears mainly in intensive care units, increasing the mortality rate up to $43 \%$. It also takes part in the development of other infections, as well as in the urinary tract, soft tissues or meninges. It is one of the most important pathogens related to healthcare due to rapid spreading and ability of acquiring antibiotic resistance mechanisms. That is why it is often determined as an MDR pathogen, and additionally estimated to be responsible for about $50 \%$ of total intensive care unit antibiotic usage $[20,21,22]$.

A. baumannii increases its virulence in the hospital environment and attacks patients with numerous comorbidities, infants with low birth weight, patients with immunosuppression, elderly people with chronic diseases, such as cancers. The main factors predisposing to $A$. baumannii infection are prolonged hospitalization, mechanical ventilation and the presence of intravenous catheters. Prior treatment with a wide spectrum antibiotics, including exposition to aminoglycosides, previous blood infection, enteral tube nutrition, usage of nasogastric tube and preceding hospitalization/ stay in an Intensive Care 
Unit because of contamination risk, are also able to raise the probability of infection $[23,24]$.

Freire et al. proved that A. baumannii bacteriemia alone, among patients with cancer, is characterized by high mortality. The researchers focused mainly on XDR-ABC strains (extensively drug-resistant Acinetobacter baumanniicalcoaceticus complex). At the same time, they underlined the role of strict, proper control and medication of bacteriemia of that etiology, bearing in mind that patients with cancer experience neutropenia and additional infections at the localization of the tumour [23].

Establishing the right treatment in A. baumannii infections, especially empiric, can prove to be very difficult. Antibiotics which are typically effective are piperacillin with inhibitor (tazobactam), tigecycline, aminoglycosides, polymyxins and carbapenems (meropenem, imipenem, doripenem). Carbapenems play a critically important role in the treatment of severe infections because they have the broadest spectrum of activity and greatest potency against gram-positive and gram-negative bacteria. As a result, they are often used as 'last-line agents' or 'antibiotics of last resort' when the patient's condition does not improve or a resistant strain is suspected. Unfortunately, the recent emergence of growing drug resistance with multidrug-resistant (MDR) pathogens seriously threatens this class of lifesaving drugs [21]. In the presented case report, the isolated A. baumannii strain correspondingly showed resistance to carbapenems, but preserved sensitivity to colistin.

Ciprofloxacin used in pneumonia treatment was ineffective, although the isolated $C$. freundii strain was sensitive to it. It is possible that the sputum examination failed to isolate A. baumannii, or that during the course of treatment a co-infection occurred. As already mentioned, it is a common pathogen of respiratory tract infections. The spread of bacteria via blood should be considered as secondary; however, in retrospective analysis performed by Ballouz et al., where blood infections of $A$. baumannii etiology were studied, $63.3 \%$ of cases were primary. The other $36.7 \%$ was secondary infections, the source of which was mainly pneumonia. Acinetobacter spp. may cause blood infections, especially in critically ill patients, and it can clinically vary from mild bacteriemia to septic shock. Ballouz et al. data shows that septic shock developed in $45.5 \%$ of patients [24]. The described case report was also complicated by severe sepsis, but the implemented and modified treatment fortunately proved to be effective.

\section{CONCLUSIONS}

A predisposition to various infections increases with age because of weakening of natural defence mechanisms, occurrence of many comorbidities, more frequent hospitalizations, and possible complications of the treatment introduced. A number of patient-dependent risk factors clearly influence the infection and its course. People with risk factors, and those treated because of lung neoplasm, belong to the group of increased risk of developing respiratory tract infections. It is crucial to monitor hospitalized patients with sudden deteriorations of their state, keeping in mind the microbiological aspect. A rise in inflammatory markers and clinical symptoms indicate infection development and dictate the need for prompt diagnosis and treatment. It is very important to bear in mind that the most common etiology of bacterial infections among hospitalized immunocompromised patients are gram-negative bacilli. There exists also a possibility of mixed etiology infections or a transition of one infection into another. The pathogens can present different drug resistance profiles and mechanisms which constitutes a challenge for potentially effective antibiotic therapy, especially in small District Hospitals where, due to the lack of better drugs, there are limited options of treatment.

Non-fermenting bacilli with Acinetobacter spp., pose a growing threat for patients, especially those in intensive care units. Usage of a wide spectrum antibiotics in an empiric therapy setting and common persistent usage of the drugs from the same group, favours the selection of multidrug resistant strains and increases drug resistance in the hospital environment. Particular to this case is the coexistence of antibiotic resistance mechanisms, and making a difficult decision for therapy in small treatment centres where drug options are limited. This may be useful for other clinicians to make better decisions in similar cases.

\section{REFERENCES}

1. Didkowska J, Wojciechowska U, Czaderny K, et al. Nowotwory złośliwe w Polsce w 2017 roku. Krajowy Rejestr Nowotworów http:// onkologia.org.pl/wp-content/uploads/Nowotwory_2017.pdf (access: 2020.10.11)

2. Siegel RL, Miller KD, Jemal A. Cancer statistics, 2020. CA Cancer J Clin. 2020; 70(1): 7-30. https://doi.org/10.3322/caac.21590

3. Rancic M, Ristic L, Stankovic I. Infective complications in patients with lung cancer. Med Pregl. 2010; 63: 643-647. https://doi.org/10.2298/ MPNS1010643R

4. Ferri M, Ranucci E, Romagnoli P, Giaccone V. Antimicrobial resistance: A global emerging threat to public health systems. Crit Rev Food Sci Nutr. 2017; 57(13): 2857-2876. https://doi.org/10.1080/10408398.201 5.1077192

5. Nichols L, Saunders R, Knollmann FD. Causes of death of patients with lung cancer. Arch Pathol Lab Med. 2012; 136(12): 1552-1557. https:// doi.org/10.5858/arpa.2011-0521-OA

6. Hayat MJ, Howlader N, Reichman ME, et al. Cancer statistics, trends, and multiple primary cancer analyses from the Surveillance, Epidemiology, and End Results (SEER) Program. Oncologist. 2007; 12(1): 20-37. https://doi.org/10.1634/theoncologist.12-1-20

7. Mayo Clinic. Diseases and conditions: Lung cancer. Retrieved from https://www.mayoclinic.org/diseases-conditions/lung-cancer/ symptoms-causes/syc-20374620 (access: 2020.10.10)

8. Nikonorow E, Baraniak A, Gniadkowski M. Oporność bakterii z rodziny Enterobacteriaceae na antybiotyki $\beta$-laktamowe wynikająca z wytwarzania $\beta$-laktamaz. Post Mikrobiol. 2013; 52(3): 261-271.

9. Gniadkowski M, Żabicka D, Hryniewicz W. Rekomendacje doboru testów do oznaczania wrażliwości bakterii na antybiotyki i chemioterapeutyki 2009: Oznaczanie wrażliwości pałeczek Gramujemnych. Rekomendacje KORLD 2009; 1-48. http://www.korld.edu. pl/pdf/02-Rek2009-Paleczki_z_rodziny_Enterobacteriaceae.pdf] (access 2020.08.10)

10. Evans BA, Amyes SG. OXA $\beta$-lactamases. Clin Microbiol Rev. 2014; 27(2): 241-263. doi: 10.1128/CMR.00117-13. https://doi.org/10.1128/ CMR.00117-13

11. Wong JL, Evans SE. Bacterial Pneumonia in Patients with Cancer: Novel Risk Factors and Management. Clin Chest Med. 2017; 38(2): 263-277. https://doi.org/10.1016/j.ccm.2016.12.005

12. Mohanty S, Singhal R, Sood S, et al. Citrobacter infections in a tertiary care hospital in Northern India. J Infect. 2007; 54(1): 58-64. https:// doi.org/10.1016/j.jinf.2006.01.015

13. Rezaei M, Akya A, Elahi A, et al. The clonal relationship among the Citrobacter freundii isolated from the main hospital in Kermanshah, west of Iran. Iran J Microbiol. 2016; 8(3): 175-180.

14. Lee $\mathrm{CH}$, Lee $\mathrm{YT}$, Kung $\mathrm{CH}$, et al. Risk factors of communityonset urinary tract infections caused by plasmid-mediated AmpC $\beta$-lactamase-producing Enterobacteriaceae. J Microbiol Immunol Infect. 2015; 48(3): 269-275. https://doi.org/10.1016/j.jmii.2013.08.010 
15. Zhang R, Yang L, Cai JC, et al. High-level carbapenem resistance in a Citrobacter freundii clinical isolate is due to a combination of KPC-2 production and decreased porin expression. J Med Microbiol. 2008; 57(Pt 3): 332-337. https://doi.org/10.1099/jmm.0.47576-0

16. Hanson ND, Sanders CC. Regulation of inducible AmpC betalactamase expression among Enterobacteriaceae. Curr Pharm Des. 1999; 5(11): 881-894.

17. Liu LH, Wang NY, Wu AY, et al. Citrobacter freundii bacteremia: Risk factors of mortality and prevalence of resistance genes. J Microbiol Immunol Infect. 2018; 51(4): 565-572. https://doi.org/10.1016/j. jmii.2016.08.016

18. Rodríguez-Baño J, Gutiérrez-Gutiérrez B, Machuca I, et al. Treatment of Infections Caused by Extended-Spectrum-Beta-Lactamase-, AmpC-, and Carbapenemase-Producing Enterobacteriaceae. Clin Microbiol Rev. 2018; 31(2): e00079-17. https://doi.org/10.1128/CMR.00079-17

19. Mohan S, Agarwal J, Srivastava R, Singh M. Observations on Citrobacter species from a tertiary care health center with special reference to multidrug resistance and presence of CTX-M gene. Indian J Pathol Microbiol. 2014; 57(3): 439-441. https://doi.org/10.4103/0377-4929.138746

20. Greene C, Vadlamudi G, Newton D, et al. The influence of biofilm formation and multidrug resistance on environmental survival of clinical and environmental isolates of Acinetobacter baumannii.
Am J Infect Control. 2016; 44(5): e65-e71. https://doi.org/10.1016/j. ajic.2015.12.012

21. Michalopoulos A, Falagas ME. Treatment of Acinetobacter infections. Expert Opin Pharmacother. 2010; 11(5): 779-788. https://doi. org/10.1517/14656561003596350

22. Demirdal T, Sari US, Nemli SA. Is inhaled colistin beneficial in ventilator associated pneumonia or nosocomial pneumonia caused by Acinetobacter baumannii? Ann Clin Microbiol Antimicrob. 2016; 15: 11. https://doi.org/10.1186/s12941-016-0123-7

23. Freire MP, de Oliveira Garcia D, Garcia CP, et al. Bloodstream infection caused by extensively drug-resistant Acinetobacter baumannii in cancer patients: high mortality associated with delayed treatment rather than with the degree of neutropenia. Clin Microbiol Infect. 2016; 22(4): 352-358. https://doi.org/10.1016/j.cmi.2015.12.010

24. Asif M, Alvi IA, Rehman SU. Insight into Acinetobacter baumannii: pathogenesis, global resistance, mechanisms of resistance, treatment options, and alternative modalities. Infect Drug Resist. 2018; 11: 12491260. https://doi.org/10.2147/IDR.S166750

25. Ballouz T, Aridi J, Afif C, et al. Risk Factors, Clinical Presentation, and Outcome of Acinetobacter baumannii Bacteremia. Front Cell Infect Microbiol. 2017; 7: 156. https://doi.org/10.3389/fcimb.2017.00156 